International Journal of

Advanced Science and Convergence

\title{
Technology Education of Artificial Intelligence Education, by Artificial Intelligence, for Artificial Intelligence, shall not perish from Korea?
}

\author{
Sung-ae Kim ${ }^{1}$ \\ ${ }^{1}$ Professor, Department of Liberal Arts, Duksung Women's University, Seoul, 01369, South Korea
}

\begin{abstract}
Background/Objectives: The Korean Ministry of Education is planning to introduce artificial intelligence education into the 2022 revised curriculum, which will be applied from 2025. To this end, it has been announced that related learning materials will be developed starting next year to expand Al education in Elementary, Middle and High school classes. To this end, it has been announced that related learning materials will be developed starting next year to expand Al education in Elementary, Middle and High school classes. It is said that high schools will be opening new Al-related courses from next year. As everyone calls artificial intelligence technology, there is no technology education anywhere else in artificial intelligence education. But this scene is very familiar. It's like watching a déjà vu. It was the same when SW education was introduced into the 2015 revised curriculum. Although SW is an area of technology, there was no technology education in SW education. As a result, technology teachers are facing big and small difficulties in the school field. But wouldn't it be possible to experience the same situation again like Deja Vu? At first, I didn't know how to suffer so far, so even if I did, I couldn't go through the same thing twice. So, what should our respected technology teachers prepare for?
\end{abstract}

Index Terms Artificial Intelligence Education, Technology and Engineering Education, Future Education, 2022 revised curriculum in South Korea

Corresponding author : Sung-ae Kim

techsakim@duksung.ac.kr

- Manuscript received February 3, 2021.

- Revised March 4, 2021 ; Accepted March 20, 2021

- Date of publication March 31, 2021.

(C) The Academic Society of Convergence Science Inc.

2619-8150 @ 2019 IJASC. Personal use is permitted, but republication/redistribution requires IJASC permission. 


\section{INTRODUCTION}

The digital transformation triggered by the 4 th Industrial Revolution is rapidly spreading across all areas of politics, economy, society, and culture, changing our lives. We live with artificial intelligence every moment, such as clicking videos recommended by YouTube, ordering food recommended by delivery apps, and purchasing products recommended by shopping malls. Artificial intelligence technology, which is improving performance at an exponential rate, is not just driving disruptive innovations, it is bringing about unimaginable changes throughout life. As the importance of knowledge about artificial intelligence technology penetrating our lives and society as a whole has emerged, the AI education craze is blowing in Korea from not only universities, but also elementary, middle and high school students.

The government systematizes artificial intelligence education at universities through the AI/SW-centered university project and is laying the foundation for artificial intelligence education in elementary, middle, and high schools by establishing a comprehensive AI education plan [1]. The Ministry of Education [1] announced the introduction of artificial intelligence education in the 2022 revised curriculum, introducing 'Basics of $\mathrm{AI}$ ' and 'AI mathematics" to career elective courses of Technology and Home-economics subject in high school, and strengthening AI convergence education capabilities through 38 graduate schools For retraining. However, despite these government policies, confusion is increasing in unprepared frontline sites, and concerns from parents as well as teachers are increasing [2,3]. This is because artificial intelligence education focuses on learning a new technology called artificial intelligence. Primary and secondary AI education is not a vocational education, but a general education, and artificial intelligence technology should be used to cultivate the subject competencies pursued by each subject. The government and local governments are also focusing on convergence education and recommending ways to utilize artificial intelligence technology in various subjects without subject limitation. This is because primary and secondary AI education should not be vocational education that focuses on mass-producing developers, but education that focuses on cultivating artificial intelligence literacy. Therefore, AI education is not limited to a single field of computer science, but rather several humanities subjects $[4,5,6]$ and science, technology, and engineering. Convergence with various fields should be emphasized more. Although the topic of artificial intelligence education is the convergence of various subjects, information education has also formed an information education expansion promotion team and argues that primary and secondary information education should be expanded externally for artificial intelligence education[7]. Even though artificial intelligence technology is included in one area of technology education[8], research on artificial intelligence education in elementary and secondary technology education is very poor[9,10]. In addition, the direction and position of technology education in artificial intelligence education introduced in the 2022 revised curriculum is very unclear. Accordingly, the direction and tasks for artificial intelligence education in terms of technology education were explored.

\section{Artificial InTelligence EDUCATION IN ELEMENTARY, MIDDLE AND HIGH SCHOOL AT KOREA}

The biggest weakness of AI education for all is that the complexity of the content covered in AI education feels difficult for students. Therefore, the U.S. has developed and is running a liberal arts lecture related to artificial intelligence, which is an essential skill for non-majors who feel artificial intelligence difficult $[4,5,6]$. It teaches the concept of artificial intelligence using games and robots, extracts social issues of artificial intelligence through various media such as movies and videos, leads to discussion, and explains artificial intelligence in connection with animal behavior. He is designing an introductory course to artificial intelligence through various efforts [4,5]. As these efforts were transferred to elementary and secondary schools, the need for artificial intelligence education began to arise.

Looking at the international status of AI education, China was the first country that made AI education mandatory. It is known that China has the most data necessary for the development of artificial intelligence technology by actively taking advantage of the government's control over all infrastructure [11]. Taking advantage of these strengths, it is accelerating the development of artificial intelligence technology, and at the same time, it is receiving full support from the government in education, such as developing the world's first artificial intelligence textbook for each grade [12]. Not only China, but also Japan, which operates a curriculum centered on data science, and Israel and India, which reorganize and operate existing SW education into artificial intelligence education, are introducing and operating artificial intelligence education $[13,14]$. As such, the 
demand for artificial intelligence education has spread around the world, and the Association for the Advancement of Artificial Intelligence (AAAI) and the Computer Science Teachers Association (CSTA) have begun work to develop guidelines for teaching artificial intelligence since 2018[15]. As a result, five big ideas of artificial intelligence that all students should know are presented as shown in Fig. 1 [16] and are being translated and used in various languages [17]. AI4K12 not only established the concept of artificial intelligence education through five big ideas, such as perception, expression and reasoning, learning, social influence, and natural interaction, but also collected opinions from AI educators around the world including the United States. It is constantly revising and supplementing the guidelines for artificial intelligence education based on five big ideas.

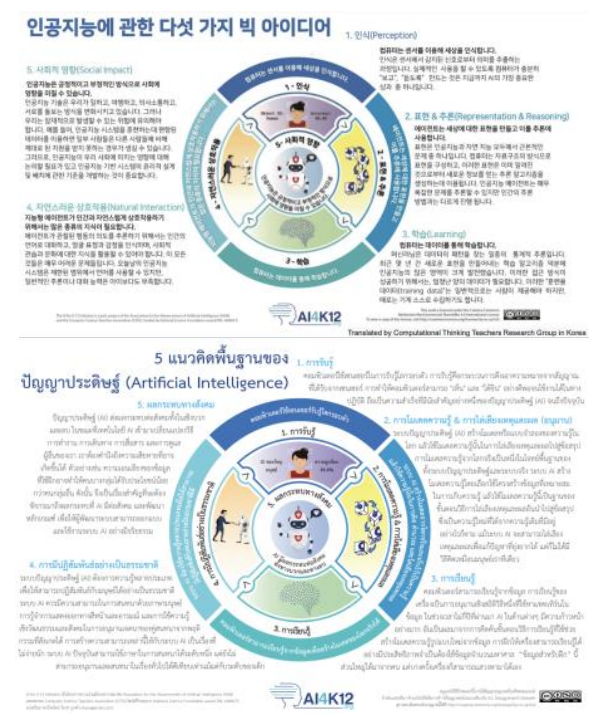

Fig. 1. 5 Big Ideas Translated and Distributed in various languages [17].

In Korea, an artificial intelligence education framework was also announced through the Korean Artificial Intelligence Education Association based on educational topics and contents from a universal education perspective. It divides the major themes of artificial intelligence education into problems and exploration, knowledge and reasoning, data and learning, sense and cognition, language and communication, action and action, and artificial intelligence and society. Based on this, artificial intelligence basic education and artificial intelligence expansion Education was categorized [18].

Along with this, it is the artificial intelligence ethics education that is notable. Just as social influence, one of the five big ideas of AI4K12, is the basis for the remaining big ideas, perception, expression and reasoning, learning, and natural interactions, in Korea, through the AI national strategy announced in 2019 [19]. In addition to artificial intelligence literacy education, artificial intelligence ethics education was emphasized.

According to one study, because of conducting artificial intelligence ethics education along with the principles of artificial intelligence technology to middle school students who are new to artificial intelligence, it was confirmed that a positive change in perception of artificial intelligence was achieved as well as high class satisfaction [13].

Amidst ethical and social issues related to artificial intelligence such as Microsoft's Tay incident and Kakao's Iruda incident around the world, artificial intelligence ethics education is essential not only for adults but also for elementary, middle, and high school students. With various AI education policies established and operated in various countries around the world, AI education from elementary, middle, and high schools to liberal arts and majors is being further strengthened.

\section{TeChNology Education AND ARTIFICIAL INTELLIGENCE EDUCATION}

When Korea announced its 'National Strategy of Artificial Intelligence' in December 2019, through a detailed strategy called 'A country that makes the most of artificial intelligence', Korea made the essentialization of AI literacy education and a detailed strategy called 'People-centered AI implementation. It emphasized the development of artificial intelligence ethics curriculum. Accordingly, the interest in artificial intelligence education of the whole people from elementary, middle, high school, as well as college and lifelong education is increasing, and voices of concern are also growing. During this, in November, the government announced the "Artificial Intelligence Education Policy Directions and Core Tasks" [1] and suggested the direction for Korean education to go in the age of artificial intelligence.

Among the directions for artificial intelligence education announced by the government, the remarkable part of our technology education is 'education in accordance with the times' in preparation for the changes in the future society where humans and artificial intelligence coexist. Based on this, the government emphasized that the paradigm of future education is shifting from the perspective of using and consumption of artificial intelligence technology to the perspective of production and creation. Today, it needs people who use artificial intelligence technology well, but in the future, it really needs a producer and creator who actively collaborates with machines to create new things. 
Already in the U.K., Finland, and other European countries, in preparation for the future digital technology society, digital technology-related education has changed from the existing consumer and user-centered education to producer and creatorcentered education in preparation for the future digital technology society. In fact, in the process of revising the "Design and Technology" curriculum, the UK changed its direction from the existing education centered on woodworking to education centered on digital technologies including sensors and microcontrollers [20]

While the Korean government defines the future keywords of artificial intelligence education as producers, creators, makers, and creators, the subject that this keyword fits best is our technology education. This is because our technology education is already focusing on production and creation. From the curriculum of the past to the present, our technology education has been transformed from the viewpoint of use and consumption to the viewpoint of production and creation.

As the technological problem-solving process was displayed on the front of the curriculum, technology education that solved uniform and structured problems changed to technology education that solves semi-structured or unstructured problems. Technology teachers at each school have built a technical workshop, infinite loss, and a maker space within the school as a space for production and creation through the support of government agencies, local governments, and the Office of Education. It is still being practiced. Therefore, technology education is a subject that has been established in advance according to the government's future education policy.

Also, in general, artificial intelligence education considers artificial intelligence technology as a new technology and thinks only that new knowledge to be learned is added, which is not desirable. Artificial intelligence education is a technology education centered on production and creation. In the future society where our students will live, what are the competencies required of humans in the age of artificial intelligence, and what education should we do to cultivate them? do. The answer to this can be said to be the policy direction and task for the future of our children.

In the name of introducing SW education to the 2015 revised curriculum, the information subject was designated as a mandatory subject for middle school and SW was included in the elementary school practical course, which received full support from the whole people. This is because the goal is to develop logical thinking skills and problem-solving skills through SW education. However, in most schools, education was not as in-depth as expected, and in the end, parents turned to the private education market to take in-depth classes.

Nevertheless, with the introduction of SW education into the school curriculum, with the formula of ' $\mathrm{SW}$ education = information education', even HW (Hardware) including software from autonomous vehicles, robots, and drones to be recognized as SW(Software) As a result, technologyoriented society was recognized only as 'SWoriented society'. Through this, the information subject was successfully settled in middle and high schools by stating that 'software education for all' should be provided because it is a software-oriented society.

Despite the successful establishment of the information curriculum for SW education, when SW education was first introduced in the 2015 revised curriculum, there was an expectation that it would be possible to learn coding, but the practical effect was insufficient and there was a very large gap depending on the infrastructure depending on the region. Therefore, despite the announcement that artificial intelligence education has been introduced, parents are not shaken much more than when software education was mandated.

Teachers also agree with the need for artificial intelligence education but criticizes that COVID-19 is causing another confusion in the school scene. In addition, questions about whether public education alone sufficiently master artificial intelligence education can, how much current teachers can develop the expertise of artificial intelligence education, and how much teachers and students can learn and follow the rapidly changing artificial intelligence technology. There are many voices of concern, such as the concept of artificial intelligence education and the uncertainty of the educational content.

\section{DIRECTION OF ARTIFICIAL INTELLIGENCE EDUCATION IN TECHNOLOGY EDUCATION}

Even in this situation, we must remember that another tsunami called artificial intelligence education policy is coming to the educational field, which is not long after the tsunami of SW education policy has passed. In the face of natural disasters, it is said that any preparation or any response is useless, but the tsunami of artificial intelligence education policy is clearly man-made, so you can prepare and cope with any number of times.

In other words, you must be prepared and dealt with. The word contrast and the word coping have as much nuances as their meaning. Taking appropriate action for an event is called coping and preparing in advance to respond to something is called 
preparation. We must also prepare for and cope with the situation of artificial intelligence education. Which direction should it be?

First, as mentioned earlier, the starting point when we want to prepare for artificial intelligence education is that students should be the starting point. In other words, "In technology education, I do artificial intelligence education. Through my artificial intelligence education, my students will be able to cultivate $\bigcirc \bigcirc$ competencies and abilities." It can be said that the priority is to hold on to that. Depending on what this is, the direction of the teacher's education will change, so it is very important to always establish this part.

Most of us provide technology education with a focus on cultivating technological problem-solving skills, creativity, and social collaboration skills. That is why we can educate production and creation and find and solve problems in real life. Therefore, prior to artificial intelligence education, there must be one's own formulation of artificial intelligence education viewed from technology education.

Second, it is necessary to make use of the strengths of technology education. In other words, it is necessary to consider what only technology education can do.

In 2004, when I started robot education through special aptitude education at the school where I was first appointed, there were not many teachers in the country who were teaching robots. Since there was no place where I could take a robot-related job training, I went to training for a teaching aid robot company for the heads of the academy. And even when I practiced really hard to win a prize at a domestic competition and go out to a world competition, only the heads of the academy and vice presidents were all around.

As he continued to dominate the domestic competition, the head of a parent academy asked for his current salary, asking him to come to his academy. Like artificial intelligence education, it was gaining sensational popularity in the private education market, and even now, he was learning robot education by paying a considerable amount of money.

In the meantime, robot science was included as a pilot section in the youth science exploration contest from 2005, and robot education began to attract attention at school sites, but the target of interest was science teachers. When I was teaching robot education-related job training and self-training instructors, I remember that most of the subjects were science. As the years have passed, robots are now attracting attention to those in charge of SW education among elementary school teachers and information teachers. In addition, information teachers are also interested in physical computing education. How about artificial intelligence education? In AI education job training, it is faster to find a science teacher or an information teacher than to find a technology teacher.

Why are robots, software, and physical computing that seem to be our domains becoming everyone's education? The same goes for 3D printers and drones.

Isn't it because it was tool-centered education that anyone can tackle? Since I was given an education that knows how to handle tools, isn't it that I am teaching only the basics in the way of squeezing watermelons? And yet, is it not just packaging that is educating something extraordinary on the outside?

At one time, I was upset, saying that robots are technology, physical computing is technology, and software is technology, but why take all of us from other subjects.

However, I thought that the answer could be to show differentiation through education that only we can do through robots, software, physical computing, $3 \mathrm{D}$ printers, and drones. It is unfortunate that it becomes a teacher's competency, but...

While conducting robot education and physical computing education, he emphasized a lot of hardware. The hardware was designed using mechanical elements. I thought that this might be our strength, but it was an area that only we could do.

One day, I had trained the automata made by physical computing and woodwork through team teaching. It was a job of cutting machine elements through woodworking, making a drive part through it, and installing sensors and motors for automation. It is this by looking at the words from the students' mouths. There is something I thought this was our strength.

\footnotetext{
"I programmed perfectly without errors. But no matter how perfect the software is, it's useless. If you don't make the hardware well, it won't work. I didn't know the hardware was so important." (student A)
}

To realize that it is not just software alone $\sim$ This can be said to be the foundation on which our strength can be. What others can't do! Something that you can't do in other subjects! I wonder if we should try to combine it with artificial intelligence in our technology education. Of course, the first of this attempt is 'What competences (abilities) will students cultivate?", but..

Since it is an area that everyone can easily invade, the most important point is not to be frustrated and criticized, but to reestablish and coordinate technology education into an area of education that only we can do. Since it is an area that everyone can easily invade, the most important point is not to be frustrated and criticized, but to reestablish and coordinate technology education into an area of 
education that only we can do.

third. Artificial intelligence has now become an area that has to be dealt with in all fields, not in a specific field. Therefore, artificial intelligence education must be conducted unconditionally in technology education, and investment is required for this.

Even when software education started and artificial intelligence education started, the interest of technology teachers is relatively small compared to that of other subject teachers. The instructor who was conducting the robot training once said the following.

"The same education program was conducted
for science teachers, information teachers, and
technology teachers, but there was a common
characteristic that technology teachers showed.
The activity in the part of making hardware is
very active, but he is very passive in the part
of programming. However, they all say they
know, but I found a common point that they
do not program themselves."
(instructor A)

Now, for artificial intelligence education, professors, and teachers in the field of technology education must invest time in preparing and learning. There is a way to learn through books, and there is a way to learn through YouTube. If it is difficult to do it on your own, look for various training programs. If you do not have training, you can make a study through a national technology teacher meeting or with local technology teachers. A conclusion section is not required. Although a conclusion may review the main points of the paper, do not replicate the abstract in the conclusion. A conclusion might elaborate on the importance of the work or suggest applications and extensions.

In fact, we don't feel a threat to our livelihoods just because we don't learn artificial intelligence. Even if you don't learn it, you may not be hit hard to take a technology class in the current curriculum.

However, it is not a threat right now, but it poses a very big threat to the future of technology education. Maybe it could influence the existence of technology subjects. Since there is a technology teacher only when there is technology education, shouldn't our efforts be so desperate? As a technology teacher, it may be a natural part to have much more sensitivity to new technologies, so now is the time to invest time and effort in preparing for the introduction of artificial intelligence education for technology education and to proceed with research.

Fourth, it is also necessary to plan to collaborate artificial intelligence education with areas of interest and excellence. In other words, a method of integrating artificial intelligence into the field of technology education that we are good at is required.
As I think that woodworking and IT should coexist, is it not an education that cannot keep pace with the times at the present time when all issues are concentrated in artificial intelligence education and software education, seeing only woodworking performances continue to appear in technology education? I think about it. However, as software education came out and technology education lost its identity in the field and was drifting away, my thoughts began to change gradually.

When we see that we are often called "Science Lab", we expect that a science teacher will do it for everyone. In general, I think that teachers in other subjects cannot run this class at school.

However, when words such as inventions, robots, and drones are attached, even 3D printers these days tend to be used a lot in science departments. Some schools are called science, and recently, some are called information. Of course, I think it's technology, but.

There was something that appeared at this time, so it was woodworking. The manager who retired from the previous school was a technology teacher, but he was a master of woodworking. There are many woodworking works of the manager in the school... People think that the woodworking class at this time would be a skill. It is very rare that both science and information are their domain.

In the age of software, in the age of artificial intelligence, we can combine software or artificial intelligence with education using woodworking, which is our own domain. Or, if a technology teacher is interested in automobiles, he can link artificial intelligence education to automobiles. In addition, if a technology teacher is interested in architecture, they can apply artificial intelligence education to architecture. Regardless of any technology, software or artificial intelligence can be combined, so it can be said that technology-centered convergence education is natural. Therefore, it would be a good idea to start by integrating artificial intelligence into areas where the technology teacher himself is good at or is interested.

Fifth, there is a need for a self-supporting and voluntary research team to be organized.

To make artificial intelligence stand firm in technology education, it is necessary to consider a plan to establish a new artificial intelligence education research team at the national technology teacher meeting. We are a powerful educational network that has produced more than 50 Young Maker contents. Technology teachers nationwide boast a huge number of hidden masters. Therefore, it is necessary to systematize artificial intelligence education research in technology education, such as teacher training and development of educational materials, and support for the development of 
research materials by teachers through the establishment of a new technology education research team or convergence education research team at the national technology teacher meeting.

This should be discussed not only with the development of simple educational materials, but also the issue of educational policy and "presentation of directions for convergence of artificial intelligence education in technology education" through media reports. In addition, it is necessary to conduct research on the next-generation technology curriculum in relation to artificial intelligence education. For example, the information subject has been making joint efforts to reform the curriculum through regular monthly workshops since before 2018. Professors of computer education at the University of Education, professors of computer education at the University of Education, professors of liberal arts majors in computer education at general universities, and professors of computer engineering at general universities continued to discuss the standard model of the next generation software curriculum. We have opened a forum and released a standard model for artificial intelligence and convergence attempts. These efforts and the alliance with general colleges as well as school and colleges have great implications for us in that they have become the basis for establishing a roadmap from elementary and secondary information education to liberal arts education and major education in universities. It is also necessary to benchmark the parts that can be benchmarked in our technology education preparing for artificial intelligence education. It is necessary to establish a strategy and roadmap for the next-generation curriculum through a network of professors related to technology education, professors from the technology education department of the College of Education, professors related to technology education and technology education at general universities, and a teacher network. have. This is not just an effort by us, but it is also necessary to present a model built by planning a large forum and to make it public. Our technology education has pursued substantial education rather than show-style education. However, with the introduction of software education in the 2015 revised curriculum and the targeting of technology and Homeeconomics education as a public enemy of information education, many technology teachers in the field are experiencing realistic difficulties such as reducing the number of hours and proportions, and technology and Home-economics education courses are designated as elective courses for high schools. As a result, high schools are experiencing a lot of difficulties, such as more and more places that do not provide technology education.

As public opinion has formed that it is too uncomfortable to do one hour per week for information subject at school, schools are also trying to reduce technology class time and increase information class time, such as holding public opinion fairs as if technology and home teachers monopolize the number of hours. In this aspect, it seems necessary to systematically respond to the systematic response and expression of the media.

\section{Conclusion}

This study proposed the development direction and action plan from the perspective of technology and engineering education in elementary, middle, and high schools in relation to artificial intelligence education to be introduced in the 2022 revised curriculum in Korea. To this end, we examined artificial intelligence education in Korea's artificial intelligence education, technology and engineering education oligopoly, and derived development directions and action plans based on reflective thinking in the light of the past and present. The research results are as follows.

First, the first step in preparing for the introduction of artificial intelligence education in technology and engineering education should be students.

Second, research on what only technology education can do by taking advantage of the strengths of technology education should be continued. This study proposed the development direction and action plan from the perspective of technology and engineering education in elementary, middle, and high schools in relation to artificial intelligence education to be introduced in the 2022 revised curriculum in Korea. To this end, we examined artificial intelligence education in Korea's artificial intelligence education, technology and engineering education oligopoly, and derived development directions and action plans based on reflective thinking in the light of the past and present. The research results are as follows.

First, the first step in preparing for the introduction of artificial intelligence education in technology and engineering education should be students.

Second, research on what only technology education can do by taking advantage of the strengths of technology education should be continued.

Third, since artificial intelligence education is not optional, but essential, systematic preparations for this must be made in the technology and engineering education world.

Fourth, it will be a quicker start to plan a collaboration with the area that the technology teacher himself is interested in and is good at before 
proceeding with a new research.

Fifth, it is necessary to form an independent and voluntary research team so that technology teachers, technology professors, and technology education researchers should prepare artificial intelligence together. This will serve as the parent body of the promotion team for expanding technology and engineering education in the future.

I think I need to do more research and develop more strength. Let's work hard to prepare and cope with the artificial intelligence education that will come to us as technology education, technology education, and artificial intelligence for technology education become education.

\section{ACKNOWLEDGMENT}

I would like to express my special thanks of gratitude to technology teachers who give the best technology classes for middle and high school students in Korea. This work was supported in part by the Korean Technology and Engineering Teachers Association (KTETA).

\section{REFERENCES}

[1] Ministry of Education in Korea (2020). Direction and Core Tasks of Education Policy in the Age of Artificial Intelligence. Retrieved from https://www.hankyung.com/it/article/2021022809211

[2] Lee, S. and Kim, N. (January 28, 2021). There is no teacher to teach AI... The government "invest in classes as well as arts and sports teachers". The Korea Economic Daily. Retrieved https://www.hankyung.com/it/article/2021022809211

[3] Lee, J., Ha, J. (December 7, 2020). 'AI education', which will be introduced as a regular curriculum in 2025, The Chosunilbo, Retrieved from https://www.chosun.com/special/future100/fu_general/2020/ 12/07/GVNLSHNG2FATZFBPDNY5A2MOM4/.

[4] Cicirello, V. A. (2008). An interdisciplinary course on artificial intelligence designed for a liberal arts curriculum. Journal of Computing Sciences in Colleges, 23(3), 120-127. https://www.cicirello.org/publications/p120-cicirello.pdf

[5] Dooley, R. L., Hopkins, C., \& Yieh, C. L. (1988). Artificial intelligence-Bayesian analysis system for cardiac catheterization laboratory. Proceedings of the Annual International Conference of the IEEE Engineering in $\begin{array}{llll}\text { Medicine and Biology } & \text { Society. } & \end{array}$ 10.1109/IEMBS.1988.95136.

[6] Kim, S., Park, J. Y. (2020, October 30). Exploring the direction of artificial intelligence education for university liberal arts education (Presentation). Proceedings of the Journal of the Korean Society for Information and Communication Sciences Conference, 24(2), 3-5, Online: Korea.

[7] Information Education Expansion Promotion Group (2021) Proceeding of the 1st Elementary and Secondary Information (SW.AI) Education Curriculum Reorganization Innovation Forum. Retrieved from http://kcode. $\mathrm{kr} /$ resource/?uid=14\&mod=document

[8] ITEEA (2020). Standards for Technological and Engineering Literacy: Defining the Role of Technology and
Engineering in STEM Education (STEL). https://www.iteea.org/File.aspx?id=177416\&v=90d1fc43

[9] Kim, S. (2020). To prepare artificial intelligence (AI) education for technical education. 2020 KTTA technology teachers, 19, 25-29.

[10] Im. M. (2020). A Study on the Direction of Technology Education in the Age of Artificial Intelligence. Journal of the Korean Society for Practical Arts Education, 33(4), 81102. 10.24062/kpae.2020.33.4.81

[11] Park, S. (2020), China's Big Data Market Trends and Implications. Trade Focus, 2020(43).

[12] Lee, S. (2020). AI education trends and implications in China. Education Policy Forum, 325, 26-31.

[13] Kim, H., Jeon, S., Choi, S. \& Kim, S. (2020). Development and application of educational programs on understanding and social influence of artificial intelligence. Journal of the Korean Society of Computer Education, 23(2), 21-29.

[14] Im, H. (2019.7.16). Strategies for fostering manpower in major countries in response to the 4th industrial revolution. National IT Industry Promotion Agency Global ICT Issue. Retrieved

from https://www.globalict.kr/kms_upload/2019/07/138220_1.pdf

[15] Touretzky, D. S. (2018. October). What is the "AI for K-12" initiative?, AAAI Fall Symposium. Washington, DC: USA, Retrieved from https://github.com/touretzkyds/ai4k12/blob/master/document s/2018-symposium/Intro-Slides.pdf

[16] Touretzky, D. S. (2020. November). The AI4K12 Initiative: Developing National Guidelines for Teaching AI In K12(Presentation), 2020 Global SW Education Conference, Seoul: Korea. http://festival.software.kr/sympathystage/global-sw-and-ai-trainingconference/5fb35e1e9c6f210038f62ab9

[17] https://bit.ly/ai4k12-five-big-ideas

[18] Kim, T. R., Ryu, M. Y, and Han, S, K. (2020). Basic study of framework for artificial intelligence education in elementary and secondary school. Journal of Artificial Intelligence Research, 1(1), 31-42.

[19] Ministry of Science and Technology Information and Communication in Korea (December 17, 2019). Artificial Intelligence (AI) National Strategy. Retrieved from https://www.korea.kr/news/pressReleaseView.do?newsId=1 56366736

[20] Yi, S., Kim, S. (2017). Objectives and contents of the 2014 revised 'Design and Technology' subject national curriculum in England. Journal of Korean Technology Education Association, 17(2), 23-46. 